\title{
A feasibility study on two tailored interventions to improve adherence in adults with haemophilia
}

J. W. Hoefnagels ${ }^{1 *}$ (D) K. Fischer ${ }^{1}$, R. A. T. Bos ${ }^{1}$, M. H. E. Driessens ${ }^{2}$, S. L. A. Meijer ${ }^{2}$, R. E. G. Schutgens ${ }^{1}$ and

L. H. Schrijvers ${ }^{1,3}$

\begin{abstract}
Introduction: Haemophilia is a congenital bleeding disorder mainly affecting males. To prevent bleeding, patients need to perform regular intravenous injections (prophylaxis) throughout life. Non-adherence often occurs. Problems with acceptance or self-management appear to be the main reasons for non-adherence in haemophilia. The aim of this study was to test the feasibility and effects of two interventions focussed on acceptance (face-to-face) and selfmanagement (online).
\end{abstract}

Methods: Patients with severe haemophilia and acceptance or self-management problems were eligible. The faceto-face group intervention was based on Acceptance and Commitment Therapy (ACT) (8 sessions/6 months, target $N=8$ participants). The online intervention was based on a successful online programme in rheumatoid arthritis (58 modules/2 months, target $N=8$ ). Both interventions were designed according to the MRC framework in collaboration with the patient society and experts. We compared adherence (VERITAS-Pro, optimum 0), quality of life (SF-36, optimum 100) and illness perception (BIPQ, optimum 0) before start (T0) and after 2 months (T2). Feasibility criteria were as follows: completion of training by $>50 \%$ of participants and ability to collect at least $80 \%$ of outcome parameters.

Results: The face-to-face intervention was feasible (89\% enrolment and recruitment, 100\% retention). One hundred percent of the outcome parameters was collected. Results were promising: although adherence (VERITAS-Pro) was stable (from 64 to 62 points), quality of life (SF-36) showed a clinically relevant improvement (> 5 points) in five of eight domains. Illness perception (BIPQ) showed a clinically relevant increase from 47 to 39 points. Patient evaluation was positive.

The online intervention, however, was infeasible: enrolment was only 20\% (6/30). Only three patients signed informed consent (recruitment 10\%), and none completed more than one module (retention 0\%). Consequently, the online intervention was terminated.

(Continued on next page)

\footnotetext{
* Correspondence: J.W.Hoefnagels@umcutrecht.nl

${ }^{1}$ Division Internal Medicine and Dermatology, Van Creveldkliniek, University Medical Center Utrecht, PO Box 85500, 3508, GA, Utrecht, The Netherlands

Full list of author information is available at the end of the article
}

(c) The Author(s). 2020 Open Access This article is licensed under a Creative Commons Attribution 4.0 International License, which permits use, sharing, adaptation, distribution and reproduction in any medium or format, as long as you give appropriate credit to the original author(s) and the source, provide a link to the Creative Commons licence, and indicate if changes were made. The images or other third party material in this article are included in the article's Creative Commons licence, unless indicated otherwise in a credit line to the material. If material is not included in the article's Creative Commons licence and your intended use is not permitted by statutory regulation or exceeds the permitted use, you will need to obtain permission directly from the copyright holder. To view a copy of this licence, visit http://creativecommons.org/licenses/by/4.0/ The Creative Commons Public Domain Dedication waiver (http://creativecommons.org/publicdomain/zero/1.0/) applies to the data made available in this article, unless otherwise stated in a credit line to the data. 
(Continued from previous page)

Conclusion: The face-to-face acceptance intervention was considered feasible with promising results.

Unfortunately, the online intervention was infeasible and therefore terminated. These findings suggest that

adapting effective interventions to other settings does not guarantee success, despite the use of established

methodology and patient participation. Population differences (only male participants, congenital disease) could be an explanation for failure of the online intervention in haemophilia despite success in rheumatoid arthritis.

Trial registration: NL55883.041.16

Keywords: Lifelong treatment, Illness acceptance, Adherence, Acceptance and commitment therapy, Selfmanagement, Congenital disease

\section{Key messages regarding feasibility}

- What uncertainties existed regarding the feasibility? Uncertainty regarding recruitment of patients struggling with illness acceptance and selfmanagement. Uncertainty regarding the ability of patients to complete the programmes.

- What are the key feasibility findings? The face-to-face group intervention regarding illness acceptance was feasible and showed promising results on quality of life and illness acceptance with stable adherence. The online intervention was infeasible due to recruitment problems.

- What are the implications of the feasibility findings for the design of the main study?

The face-to-face intervention will be evaluated in a larger group. The online training was removed from the study.

\section{Background}

The introduction of intravenous clotting factor replacement therapy has enabled the substitution of the missing clotting factor in haemophilia [1]. This therapy has been administered to treat bleeds (on demand) or as regular replacement therapy (prophylaxis) to prevent bleeds [2]. This intravenous prophylactic treatment is selfadministered by the patient at home, approximately 3 to 3.5 times per week [1]. For effective prevention of bleeding, high adherence to this prophylactic treatment is crucial. To maintain minimum clotting factor levels and preserve joint health, prophylaxis should be continued lifelong without interruption [1].

Non-adherence to prophylaxis (i.e. $\geq 25 \%$ missed infusions, or $\geq 25 \%$ dose change and/or $30 \%$ deviation in timing [3]) occurs in approximately $50 \%$ of Dutch adults with severe haemophilia [4-7]. Non-adherence and inadequate treatment of bleeds can cause irreversible damage, especially in a joint or the central nervous system [8]. Patients who stopped or interrupted the treatment had a significantly worse joint status than patients who did not stop (HJHS: 23 vs 14 points $P=<0.01$ and Pettersson score: 16 vs 5 points $P=<0.01$ ) [9]. This joint damage eventually results in a lower quality of life and reduced labour force participation [10, 11], which stresses the importance of high adherence levels.

In a previous qualitative study, illness acceptance problems and lack of self-management skills were identified as important reasons for non-adherence [12]. Patients with acceptance problems mostly stopped prophylaxis or used prophylaxis intermittently (e.g. only on demand or skipping doses). In case of self-management problems, patients failed to administer prophylaxis due to inadequate routine, forgetfulness and the complexity of the self-management skills required [12]. Our hypothesis was that both groups could benefit from a tailored intervention to improve adherence.

Therefore, two tailored interventions were developed. The first intervention was focussed on improvement of illness acceptance using a haemophilia-adapted version of Acceptance and Commitment Therapy (ACT). The second intervention was focussed on improvement of self-management through an online programme including peer support. The aim of this study was to test the feasibility and effectiveness of both interventions (1) acceptance programme (face-to-face) and (2) selfmanagement programme (online) in patients with severe haemophilia using prophylaxis.

\section{Methods}

The study design of this feasibility study [13] is shown in Fig. 1. Patients who experience difficulties with accepting haemophilia were identified by the haemophilia treatment team and invited to join face-to-face group training: 'Living with haemophilia'. This group training comprised of seven sessions and one follow-up session, guided by a trained haemophilia caregiver (social worker and nurse). Patients who experienced difficulties with self-management skills could join an individual online training: 'Challenging your haemophilia'. This online programme included 5-8 modules, guided by a trained peer. We used the CONSORT 2010 guidelines for transparent reporting studies [14]. The trial registration is NL55883.041.16 


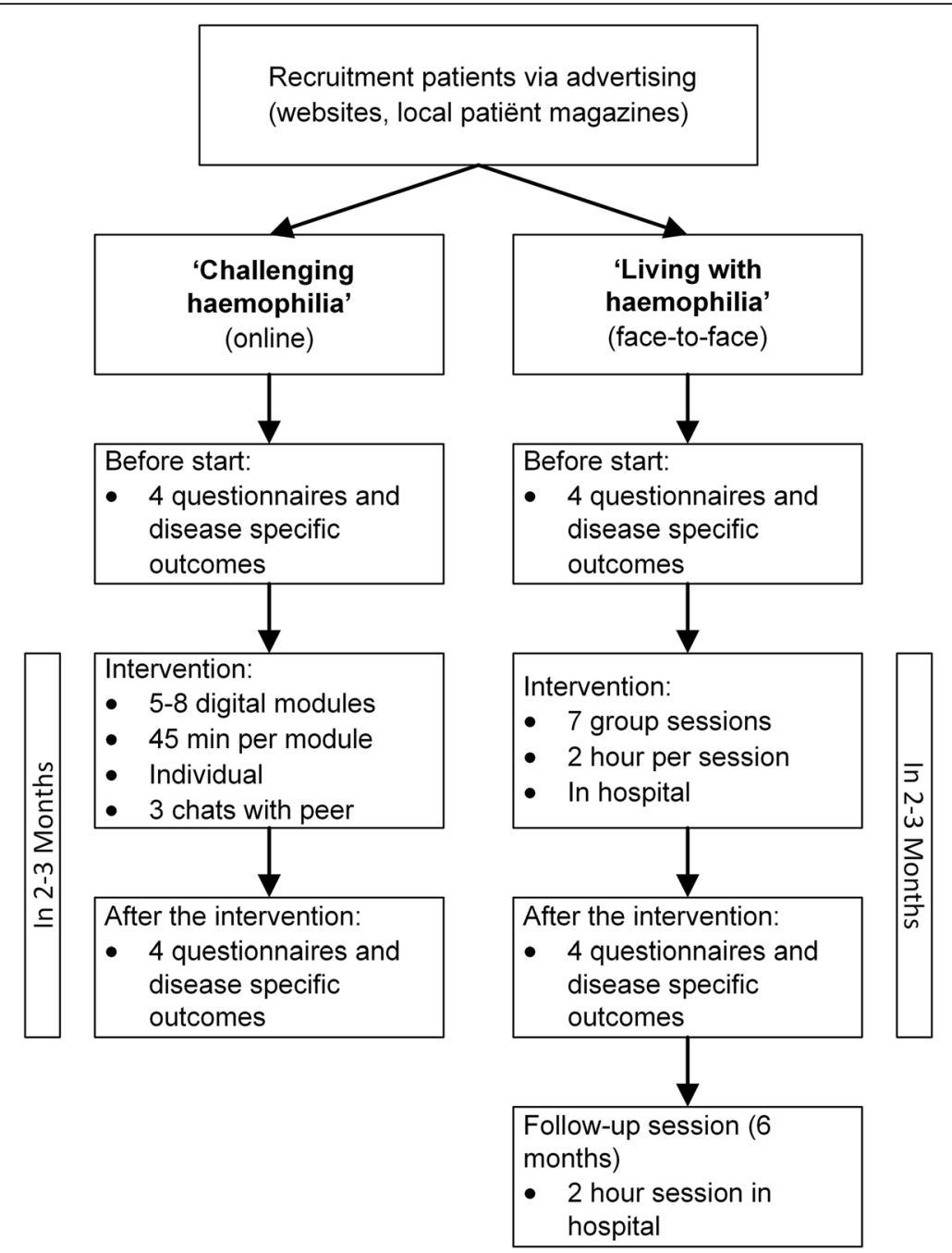

Fig. 1 Study design

Face-to-face group training focussed on acceptance: 'Living with haemophilia'

The face-to-face group training 'Living with haemophilia' was focused on improving illness acceptance, which could lead to a higher adherence to prophylaxis. This face-to-face group training was based on the Acceptance and Commitment Therapy (ACT) approach [15]. ACT is an evidence-based intervention using cognitive behaviour strategies and mindfulness, creating distancing from negative thoughts and words, emotions or physical sensations based on relational frame theory $[15,16]$. This training addressed topics like creating awareness about thoughts, discussing self-realization and exploring personal values in life (see Table 1 for more details). Group dynamics and peer contact are an important aspect of the training [17]. ACT has been successfully used in patients with a chronic disease, e.g. diabetes, HIV and chronic pain [16-19]. The original ACT training was adapted and modified to the haemophilia population, in collaboration with the department of Psychology (University Utrecht) and support of the Netherlands Haemophilia Patient Society. Based on the ACT principles and previous studies, the training consisted of seven evening-sessions of $2 \mathrm{~h}$ per session and one follow-up session after 6 months $[20,21]$. The training was fully scripted in a handbook with specific exercises and metaphors. All sessions were supervised by two ACTqualified haemophilia healthcare professionals. Because of logistical reasons, dinner was provided at the start of each session.

\section{Online training focussed on self-management: 'Challenging your haemophilia'}

The online training 'Challenging your haemophilia' was aimed at improving self-management, which could lead to a higher adherence to prophylaxis. This online 
Table 1 Overview of both trainings

\begin{tabular}{|c|c|c|}
\hline & Session/module & Aim of the session \\
\hline \multirow[t]{8}{*}{$\begin{array}{l}\text { 'Living with haemophilia' } \\
\text { (face-to-face) }\end{array}$} & 1.Control & $\begin{array}{l}\text { Creating realization in how a patient is controlling thoughts, feelings and physical sensations. } \\
\text { Discussing if this way of handling thoughts, feelings and physical sensations is effective or not. }\end{array}$ \\
\hline & 2. Acceptance & $\begin{array}{l}\text { Creating space for tiresome thoughts, feelings and physical sensations. Acceptance is part of } \\
\text { tolerating challenging experiences patients cannot get rid of. }\end{array}$ \\
\hline & $\begin{array}{l}\text { 3. Letting go of } \\
\text { thoughts }\end{array}$ & $\begin{array}{l}\text { Creating realization about thoughts and how thoughts arise. Discuss if thoughts always are effective } \\
\text { and if not how to transform them by changing them. }\end{array}$ \\
\hline & 4. Self & $\begin{array}{l}\text { Distancing ourselves from strict or rigid beliefs. Discuss who someone is and someone's identity. } \\
\text { Discussing if this vision about yourself is real or if they are just thoughts, feelings and physical } \\
\text { sensations. Discuss who someone wants to be. }\end{array}$ \\
\hline & 5. Values & $\begin{array}{l}\text { Creating realization in what a patient must do, can do and wants to do. Discussing which values are } \\
\text { important for the patient and what he really wants in life. }\end{array}$ \\
\hline & 6. Handling & $\begin{array}{l}\text { Discussing barriers, motivators and strategies for things patients really want to do. Creating } \\
\text { realization of someone's short and long time reward. Developing concrete plans. }\end{array}$ \\
\hline & $\begin{array}{l}7 \text { Looking back } \\
\text { and forward }\end{array}$ & $\begin{array}{l}\text { Summarizing on the six concepts (control, acceptance, letting go thoughts, self, values and } \\
\text { handling) and discussing used metaphors and exercises. }\end{array}$ \\
\hline & $\begin{array}{l}\text { 8. Follow-up } \\
\text { session }\end{array}$ & Discussing progress and providing additional advice. \\
\hline \multirow{7}{*}{$\begin{array}{l}\text { 'Challenging your } \\
\text { haemophilia' (online) }\end{array}$} & 1. Willing & Which values are important, learning about self-management and setting personal goals \\
\hline & 2. Knowledge & $\begin{array}{l}\text { What is haemophilia, advantage and disadvantages of haemophilia and how to intergrade } \\
\text { prophylaxis regimen into daily life }\end{array}$ \\
\hline & 3. Being able & $\begin{array}{l}\text { Infusing tips, taking and holding your own control, making responsible choices, tackling problems, } \\
\text { communication and giving and receiving feedback }\end{array}$ \\
\hline & 4. Living together & $\begin{array}{l}\text { Communication about haemophilia with others, haemophilia and its impact on relationships and } \\
\text { sexuality and impact of haemophilia on children }\end{array}$ \\
\hline & $\begin{array}{l}\text { 5. Exercise and } \\
\text { sport }\end{array}$ & $\begin{array}{l}\text { Differences in goals and levels of exercising, making consensus choices about exercising, current } \\
\text { exercise habits, impact of exercise on daily life and importance of taking a day off }\end{array}$ \\
\hline & 6. Work & The combination of work and haemophilia, potential obstacles and how to tackle them \\
\hline & 7. Looking ahead & Evaluating and setting personal goals \\
\hline
\end{tabular}

training was based on a successful comparable online training developed to improve self-management in rheumatic arthritis [22] which was based on the Arthritis Self-Management intervention (ASMP) of Stanford University [23]. This training included 5 mandatory and 3 additional modules available on a secured website. This modules including exercises, short videos, written information and the possibility to chat with trained $(N=5)$ peer trainers. The peer trainers received a formal peer trainers' training from an external specialized agency. Each module took approximately $45 \mathrm{~min}$; training had to be completed within 2 months. Details of the modules are shown in Table 1. The modules are adapted from the rheumatic arthritis format towards haemophilia, following the six steps of the Medical Research Council (MRC) framework [24]. First, the evidence base was identified by a review of the literature [25], followed by a problem analysis (theory development) [12] and a modelling process based on existing material [22]. Subsequently, a prototype was developed in collaboration with some patients and a delegation of the patient organisation (three panel sessions), followed by an evaluation of the look and feel of this prototype during a patient panel meeting followed by field usability testing [24].

\section{Participants}

For both interventions, male adults with haemophilia who were prescribed prophylactic treatment were eligible. Ability to understand written language and speak Dutch was a prerequisite. Patients diagnosed with a serious psychiatric disorder interfering with the training were not eligible. For the online training, access to internet was a prerequisite. Based on the need to follow the conversations at the online platform and to perform an oral evaluation with each participant, the maximum number of participants per group was set at eight. At the beginning of each week, all patients visiting the clinic were discussed (multidisciplinary) and eligibility was considered. Patients who were eligible were informed about this study (and both interventions) by their health care provider or through various digital platforms (different websites, newsletters of the patient society, social media). Patients received information about both interventions and could choose between both trainings based 
on their personal preference and their opinion regarding the reason for non-adherence: struggle with acceptance of haemophilia or with self-management. Informed consent was signed prior to the study.

\section{Data collection}

For both interventions, data was collected before start and directly after the intervention. The primary outcome of both interventions was adherence and secondary outcome was quality of life. Additionally, each intervention included an intervention-specific outcome measurement: participants in the face-to-face intervention completed an illness perception questionnaire and those in the online intervention completed a health education impact questionnaire.

Adherence was measured by assessment of three domains (skipping, dose changes, time changes) based on a pre-specified definition [3] and the Validated Hemophilia Regimen Treatment Adherence Scale Prophylaxis [26] (VERITAS-Pro) questionnaire, with a range from 100 to 0 and optimum score of 0 . Quality of life was measured using the Short Form-36 Health Survey Questionnaire (SF-36), with a range from 0 to 100 with an optimum score of 100 [27]. Intervention-specific secondary outcomes were illness acceptance and selfmanagement. Acceptance was assessed by the Brief Illness Perception Questionnaire (Brief IPQ), with a range from 80 to 0 with an optimum score of 0 [28], and the Health Education Impact Questionnaire (HEIQ), with a range from 0 to 5 with an optimum score of 5 [29]. In the study protocol, the minimal important difference (MID) in outcome was pre-defined. For the SF-36, the MID is established on a 5-point increase [30]. The study team has decided to use the same MID for the other questionnaires. Questionnaire details including domains, scores ranges and MID are provided in Table 2. In addition, demographic variables (age, haemophilia severity, prescribed treatment and employment) were collected before start of the intervention from patients' medical records. During the last session of the face-toface group training, patient evaluation was performed using a short focus-group interview $(10 \mathrm{~min})$. The online training was evaluated using audio-taped individual phone interviews (10 min).

\section{Data analysis}

We considered an intervention feasible if more than 50\% of the patients completed the training and if more than $80 \%$ of the data for outcome parameters could be adequately collected. If not, the study team will consider early determination of adaptation.

Additionally, according to the definitions proposed by Craig et al., feasibility was expressed by a comparison of the number of patients on prophylaxis having problems with acceptance or self-management (eligible) with the number of patients willing to participate and signed informed consent (enrolment and recruitment), number of patients that followed and completed the training (retention) and time spent on the training practicability [24]. Patient characteristics were analysed using descriptive statistics. Data were analysed using descriptive statistics and if possible a Wilcoxon test (SPSS version 21). Patient evaluations were transcribed, summarized and thematic analysed. Themes were discussed by the research team.

\section{Results}

This study was performed at the Van Creveldkliniek of the University Medical Center, Utrecht, the Netherlands. This clinic was established in 1964 and has always provided multidisciplinary treatment including designated and specialized physicians, nurses, physiotherapists and a social worker. The Van Creveldkliniek treats 250 adults with severe haemophilia, of which $\pm 50 \%$ has adherence problems, resulting in \pm 125 eligible patients overall. For this feasibility study, our aim was to include $N=8$ patients in each intervention.

\section{Face-to-face group training focussed on acceptance: 'Living with haemophilia' \\ Recruitment}

Figure 2 shows the CONSORT flow diagram, the left side concerns the face-to-face group training. Over a period of 2 months, nine patients were informed and

Table 2 Questionnaires used as outcome parameters

\begin{tabular}{|c|c|c|c|c|}
\hline & Outcome & Questionnaire & Specifications & Minimal important difference \\
\hline \multirow[t]{2}{*}{$\begin{array}{l}\text { Used in } \\
\text { both } \\
\text { interventions }\end{array}$} & Adherence & $\begin{array}{l}\text { VERITAS-Pro } \\
{[26]}\end{array}$ & $\begin{array}{l}\text { - } 6 \text { domains (Time, Dose, Plan, Remember, Skip and Communicate) } \\
\text { - } 24 \text { multiple choice questions } \\
\text { - Cumulative normalized total score ranging 0-100 }\end{array}$ & $\begin{array}{l}\text { Not official defined. We } \\
\text { considered an increase of } 5 \text { point } \\
\text { clinical relevant }\end{array}$ \\
\hline & $\begin{array}{l}\text { Quality of } \\
\text { life }\end{array}$ & SF-36 [27] & $\begin{array}{l}\text { - } 8 \text { domains (physical functioning }(\mathrm{PH}) \text {; role-physical }(\mathrm{RH}) \text {, Bodily Pain } \\
\text { (BP), General health }(\mathrm{GH}) \text {, Vitally }(\mathrm{V}) \text {, Social functioning }(\mathrm{SF}) \text {, Role- } \\
\text { emotional (RE) and mental health }(\mathrm{MH}) \text {. } \\
\text { - } 36 \text { multiple choice questions }\end{array}$ & Increase by 5 points [30] \\
\hline $\begin{array}{l}\text { Face-to-face } \\
\text { training }\end{array}$ & $\begin{array}{l}\text { Illness } \\
\text { perception }\end{array}$ & $\mathrm{BIPQ}[28]$ & $\begin{array}{l}\text { - Only a total score, no domains } \\
\text { - } 8 \text { multiple choice questions } \\
\text { - Cumulative score ranging from } 0 \text { to } 80\end{array}$ & $\begin{array}{l}\text { Not official defined. We } \\
\text { considered an increase of 5-point } \\
\text { clinical relevant }\end{array}$ \\
\hline
\end{tabular}


invited to participate in the training, all were enthusiastic to participate in the training. All patients were screened before the start of the intervention. One patient did not start, because he was receiving individual psychological treatment. All included patients $(N=8)$ completed all seven training sessions. Consequently, enrolment and recruitment was $88 \%(8 / 9)$, and retention was $100 \%(8 / 8)$.

\section{Feasibility}

On two occasions, a participant could not attend a session because of work or illness. In these cases, the continuity of the training was covered by seeing the participant individually before the start of the next session. The eventual participation retention for this intervention was $100 \%$. All participants joined the free dinner at the start of each session. The trainers evaluated the training as practical and achievable, and all outcome parameters were collected. The trainer's preparation time before every session took approximately $15-30 \mathrm{~min}$. This was considered achievable in a daily healthcare setting.

\section{Participant characteristics}

Patient and treatment characteristics are shown in Table 3. All participants had severe haemophilia A and had a median age of 38 years (range $27-51$ years). The median prescribed frequency of intravenous clotting factor use was 3.2 infusions a week (range $0-7$ ). One patient refused to take prophylactic treatment (but it was indicated), resulting in an infusion frequency of 0 .

\section{Baseline and follow-up assessments}

Baseline and follow-up assessments are shown in Fig. 3. After seven training sessions, adherence measured with the VERITAS-Pro showed a minimal improvement from baseline 64 points up to 62 points $(p=0.92)$. Quality of life (SF-36) showed clinically relevant improvements on five of the nine domains. Two mental domains showed a large improvement: role-emotional (83 points), rolephysical (63 points) and social functioning (13 points) due to emotional problems and social functioning related to work, daily activities and social relations. But surprisingly, domains that are considered related to 'physical' health such as general health (10 points) and pain (5.5 points) improved too. Furthermore, illness perception (BIPQ) improved from baseline 47 points to 39 points $(P=0.46)$ indicating a clinically relevant improvement in illness acceptance, without reaching statistical significance in this small sample.

\section{Patient evaluation}

All participants $(N=8)$ described that they were very satisfied and valued the training highly. All participants considered all sessions valuable, some preferred even more sessions. Participants felt more accepting towards haemophilia and felt less frustration regarding

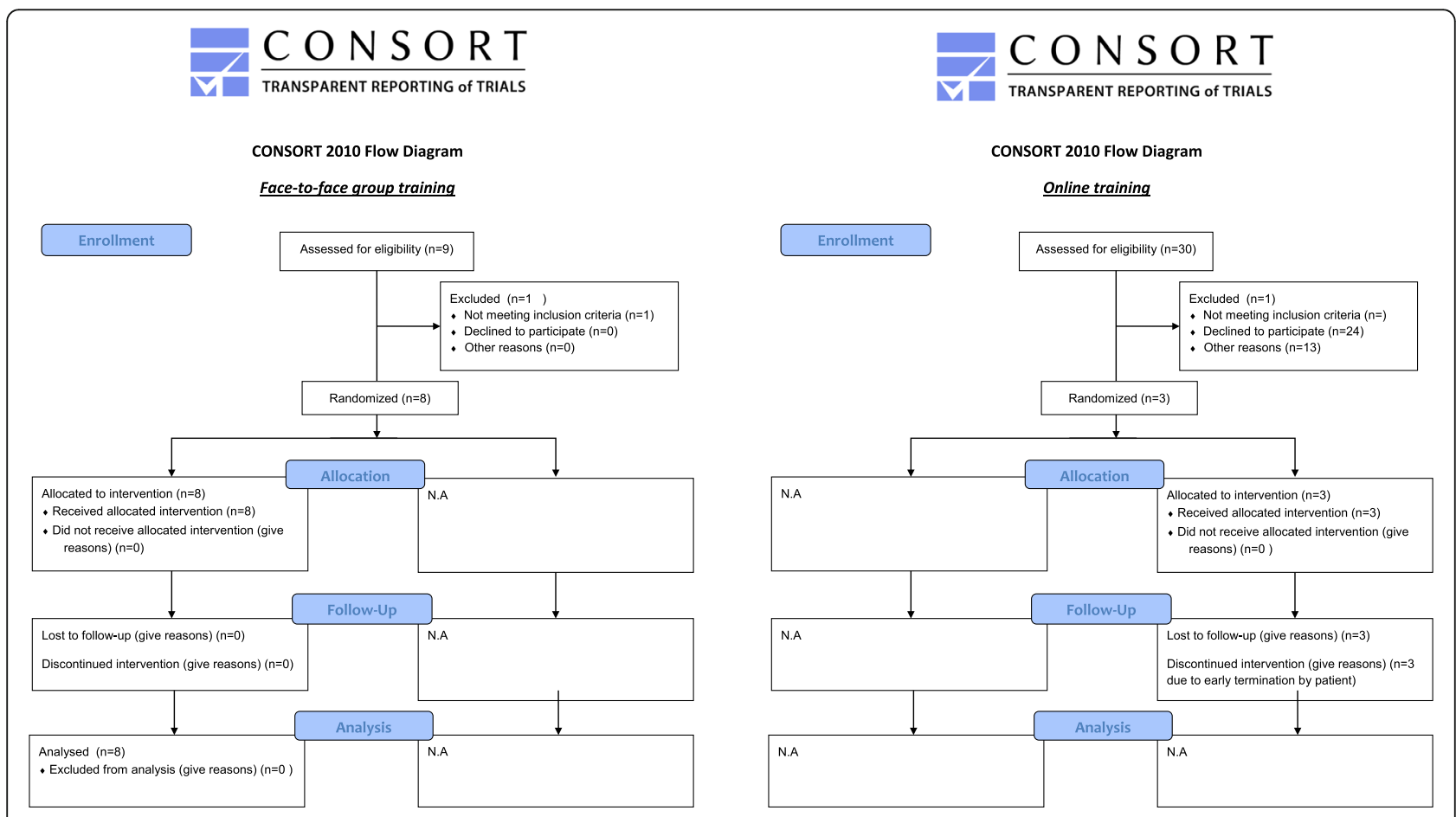

Fig. 2 CONSORT flow diagram. This flow diagram template was downloaded from the official CONSORT website [14] 


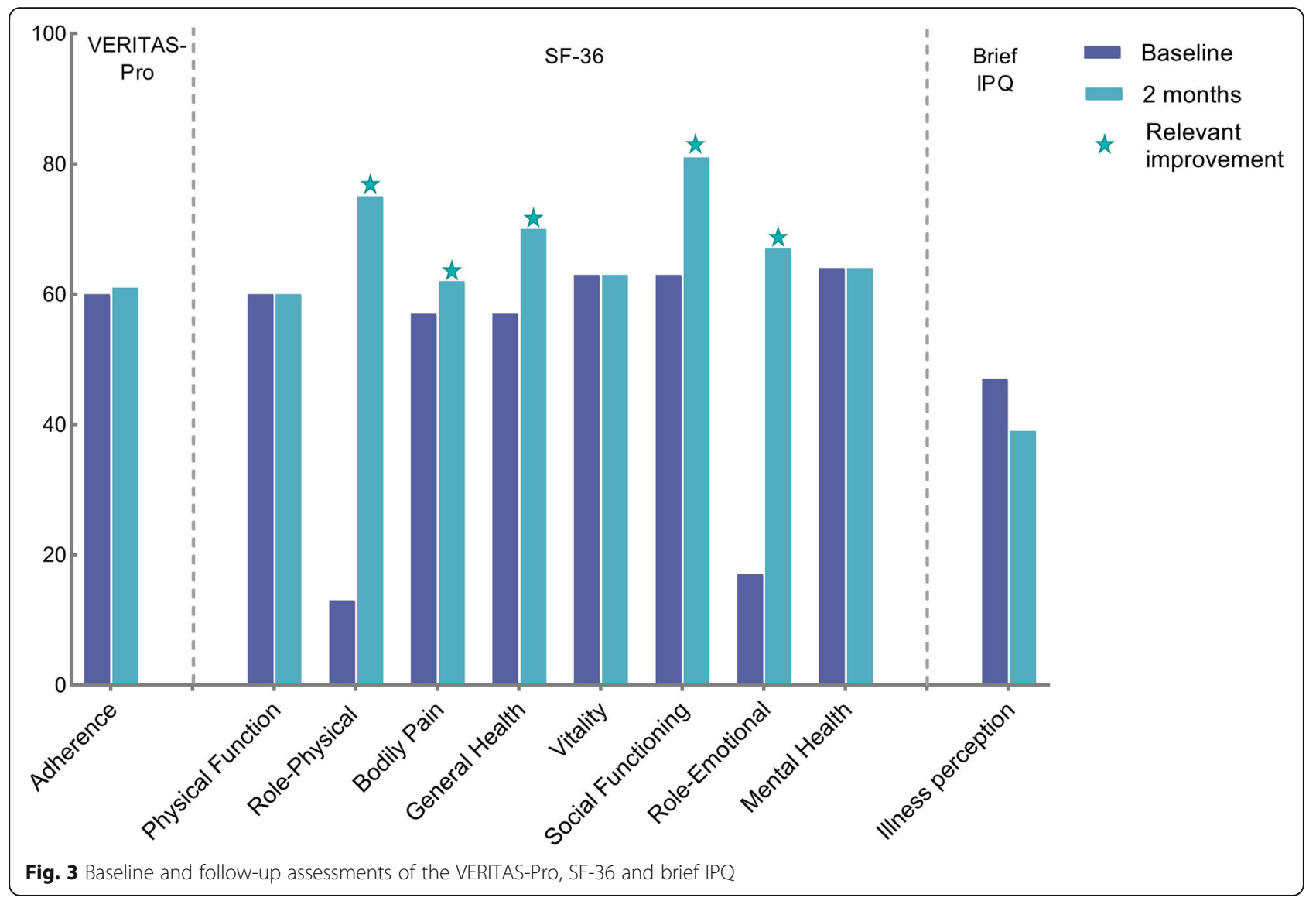

Table 3 Participant characteristics

Adherence programme $(N=8)$

Self-management programme $(N=3)$

\section{Participant characteristics}

Severe haemophilia A

Age (years)

Prescribed frequency of prophylaxis infusions per week

Employment

-Full time paid

Adherence (VERITAS-Pro, 100-0, optimum 0)

Adherence Number (\%) or median (range)

Quality of life (SF-36, 0-100, optimum 100)

Physical function

Role-physical

Bodily Pain

General health

Vitality

Social functioning

Role-emotional
$8(100 \%)$

$38.8(27-51)$

$3.2(0-7)$

$6(75 \%)$

56

60

$$
\begin{aligned}
& 3(100 \%) \\
& 24(20-32) \\
& 3(2-3) \\
& 1(33 \%)
\end{aligned}
$$

95

62

82

65

75

100 
haemophilia-related limitations. They recognized themselves in the stories from others. After the training, most participants reported experiencing more joy in daily life activities and felt more comfortable to ask for help. They also mentioned that their partners experienced positive changes.

\section{Online training focussed on self-management: 'Challenging your haemophilia' Recruitment}

Figure 2 shows the CONSORT flow diagram, the right side concerns the online training. Thirty patients were invited to participate in the training. Sixteen patients asked for more information about the training. Six were enthusiastic and willing to participate (enrolment 6/30), and only three patients returned the signed informed consent (including the baseline questionnaire) (recruitment $3 / 30$ ). None of the participant completed the online training (retention $0 / 3$ ).

\section{Feasibility}

Eventually, two participants started the training. The third one never started after signing the informed consent and completing the questionnaires, and provided no explanation. The two participants who started the training only completed the first module and quit because of personal life-changing issues, instead of lack of interest. Because of this, the retention for this intervention was $0 \%$ (Fig. 2). Because of the early termination of participants, follow-up data collection was 50\%. The study team evaluated the training as not feasible and therefore the training was discontinued.

\section{Patient characteristics}

These three participants $(N=3)$ had severe haemophilia $\mathrm{A}$ and had a median age of 24 years. Table 3 shows patient characteristics and baseline assessments.

\section{Baseline assessments}

Participants only completed the baseline questionnaire. One completed only 10/40 questions of the HEIQ. Before starting, adherence (normalized VERITAS-Pro score) median score was 56 points indicating moderate adherence. Quality of life (SF-36) domain scores varied between 62 and 100 points indicating average quality of life. Self-management (HEIQ) varied between 3.0 and 3.8 indicating moderate self-management. No follow-up data are available because of early discontinuation.

\section{Patient and peer trainer evaluation}

Two participants were still prepared to evaluate the training. Both were positive about the modules they completed. In their opinion, the format was easy to use, had a nice layout and design and included relevant information. Both were surprised about the lack of interest of other potential participants and the fact that the training was discontinued. One suggested to use this training for a younger population because of the bit scholastic format. The peer trainers $(N=3)$ were also contacted to evaluate the training. In retrospect, they suggested that the format was a bit too scholastic for adult participants. All peer trainers wondered if participants preferred face-to-face peer contact instead of an online training. He suggested that participants with haemophilia may not be aware about their own gap in knowledge, because they have been living with this disease their whole life. All trainers were disappointed, yet understood the early termination of the intervention.

\section{Discussion}

This study aimed to test the feasibility and primary effect of two interventions to improve adherence to prophylactic replacement therapy in haemophilia. The interventions consisted of a (1) face-to-face training focussed on acceptance and an (2) online programme focussed on selfmanagement. The face-to-face training was evaluated as feasible; the preliminary results were promising as adherence, quality of life and illness perception all improved. Both participants and the trainers evaluated the training very positively. The online training was evaluated as not feasible because of difficulties with the enrolment, recruitment and retention. A possible explanation could be a lack of perceived need to improve self-management in persons with haemophilia or disease-specific aspects. This result was unexpected as compared to rheumatic arthritis, where the online intervention was very successful.

Both interventions were based on the systematic and extensive research, based on the van Meijel model [31] and MRC framework [24] and extensive patient participation. This project was started with a literature review [25], followed by a problem analysis [4] and a need analysis [12]. Consequently, both interventions were based on evidence-based interventions with established effectiveness $[16,23,32-34]$. The involvement of the Netherlands Haemophilia Patient Society (NVHP) included three sessions with patient panels during the development phase, testing of the interface of the online training and participation as trainers in the online intervention. The trainers for both interventions (face-to-face and online) received specific training during the development phase. Another strength of this study lies in the use of two different methods for adherence assessment. The literature recommends the use of different approaches for evaluating adherence in patients with chronic conditions (Lam \& Fresco [35]). The VERITASPro [26] is the only disease-specific adherence questionnaire available currently. To provide more detailed information, we additionally assessed adherence according to 
the Delphi definition [3]. For the main study, evaluation of pharmacy records will be added. The study is limited by the small target population; severe haemophilia is a rare disease (1:5000 males), but non-adherence is widely prevalent at $57 \%[4,36]$. An additional important aspect is that the face-to-face training is conditional on the willingness of these men to work on their personal problems.

Concerning the face-to-face group training, this is the first ACT-based training in haemophilia. However, there is extensive experience with ACT in other chronic conditions. A systematic review showed that ACT is effective in several chronic conditions (e.g. depression, OCD, multiple sclerosis, diabetes) [32, 33], with a large effect sizes, even increasing up to 6 to 12 months after the intervention [33]. This current feasibility study had just one follow-up measurement 2 months after the last session (i.e. 6 months after the first session), and the main study will assess participants at 6 and 12 months after the training. Graham et al. stated that ACT has promising effects on selfmanagement, but reported that the effect of ACT on adherence is insufficiently demonstrated [34]. Moreover, these authors recommended the use of a randomized controlled trial (RCT) (ACT versus another behaviour strategy) instead of other study designs [34]. The preliminary results of this study showed hardly any effect on adherence (mean difference 2 points), yet the major change was on quality of life. The RCT design was considered, yet in our opinion it was unethical to let participants with problems with acceptance 'wait' in a control group. An RCT comparing two interventions was impossible as no other intervention to improve illness acceptance in haemophilia was available. A recent Cochrane review evaluated several psychological interventions for people with haemophilia [37]. It included all psychological interventions, targeted at individuals, in groups, or families [37]. This review only reported on self-administered interventions provided by technologies like a DVD and computer.

Why did the online training fail? Several potential reasons for failure were identified: age, gender and disease-specific differences. The online training was based on the comparable training for rheumatic arthritis (RA) [22, 32]. The training for RA was evaluated in both a feasibility study and a RCT [32, 38]. The feasibility study showed that the training was suitable for young adults, without recruitment problems (52\% response rate). This is also in line with a recent Cochrane review which reported that online psychological interventions are effective in young people but more difficult in adults [37]. At the time our intervention was designed, the RCT in RA was ongoing and we were unaware of its results. The eventual RCT turned out not effective related to self-efficacy but was evaluated appreciated and valuable for the participants. They included mostly young females $(88 \%$, mean age of 19 years). The Dutch RA population is nine times larger and has a larger incidence and prevalence than the Dutch haemophilia population [39]. Some studies have reported that men prefer less information about their disease, in comparison to women, and that men report lower disease-specific health literacy [40-43]. Another aspect affecting recruitment may be time since diagnosis: in diabetes, newly diagnosed ( $<1$ year) patients were more willing to participate in self-management interventions than those diagnosed 2-3 years ago [44]. Based on our experiences, it is recommended to create more awareness in disease and gender differences related to selecting an intervention.

This study has clinical and research implications. In our opinion, the results of the present study provide sufficient reasons (preliminary results, feasibility and evaluation) for continuation of the face-to-face group training into a national pre-post-test study. To evaluate the long-term effects of this intervention, data collection will be extended to 12 months follow-up in the main study. If the face-to-face group training is effective, it could be applied in daily healthcare for both severe and non-severe haemophilia patients struggling with acceptance. For clinical practice, the positive feedback from both patients and their relatives concerning the face-to-face group training has inspired us to continue. We now believe that this kind of acceptance intervention could improve daily healthcare. This acceptance and commitment therapy training is not a country- and language-specific training $[3,4]$. In our opinion, this intervention can be used in other (European) countries after proper translation. The online training was evaluated unfeasible in its current format. Based on participant evaluation, we adapted it for young teenagers who are learning self-infusion. Instead of printed information used in the past, children and parents can access an online programme with four modules. It includes educative videos, written information and tests. Nurses are able to review patients' status and answer questions online.

\section{Conclusion}

This paper described the feasibility of two tailored interventions concerning acceptance (face-to-face) and selfmanagement (online) in people with severe haemophilia. Both interventions were adapted from already existing and effective interventions. The face-to-face training was evaluated as feasible with promising preliminary results (especially on quality of life). The online training was evaluated as not feasible because of recruitment problems, and therefore, it was stopped. The failure of the online training may be attributed to age, gender and disease-specific differences between the already effective intervention and this tailored intervention in patients with severe haemophilia. 


\section{Acknowledgements}

We would like to thank all the patients who cooperated in this study, completing the questionnaires and were willing to participate in the evaluation, in particular, the ones who joined the face-to-face sessions, since it is not always easy to be open and honest when talking about sensitive and emotional topics.

\section{Authors' contributions}

J.W.H.: responsible for the interpretation of data, drafted this paper work, approved the submitted version and agreed her own contribution and contribution of other co-authors related to accuracy or integrity was appropriate. K.F.: design of the work, substantively revised this paper, approved the submitted version, and agreed her own contribution and contribution of other co-authors related to accuracy or integrity was appropriate. R.A.T.B.: design of the work, approved the submitted version and agreed his own contribution and contribution of other co-authors related to accuracy or integrity was appropriate. M.H.E.D: design of the work, approved the submitted version and has agreed her own contribution and contribution of other co-authors related to accuracy or integrity was appropriate. S.L.A.M: design of the work, approved the submitted version and has agreed his own contribution and contribution of other co-authors related to accuracy or integrity was appropriate. R.E.G.S: design of the work, approved the submitted version and has agreed his own contribution and contribution of other co-authors related to accuracy or integrity was appropriate. L.H.S: design of the work, substantively revised this paper, approved the submitted version, and agreed her own contribution and contribution of other co-authors related to accuracy or integrity was appropriate. All author(s) read and approved the final manuscript.

\section{Funding}

This work was supported by a non-restricted grant from 'The Netherlands Organisation for Health Research and Development' (ZonMW) reference number 836031006 . ZonMW approved the design of the study. The funding bodies approved the design of the study. The funding bodies had no role in the collection, analysis or interpretation of data, or in writing the manuscript.

\section{Availability of data and materials}

The datasets used and analysed during the current study are available from the corresponding author on reasonable request.

\section{Ethics approval and consent to participate}

Ethics approval was obtained by the University Medical Centre Utrecht (NL55883.041.16). All patients received oral and written information about the study and signed informed consent prior to the start of both interventions.

\section{Consent for publication}

Not applicable

\section{Competing interests}

The authors declare that they have no competing interests.

\section{Author details}

'Division Internal Medicine and Dermatology, Van Creveldkliniek, University Medical Center Utrecht, PO Box 85500, 3508, GA, Utrecht, The Netherlands. ${ }^{2}$ Netherlands Haemophilia Patient Society (NVHP), Nijkerk, The Netherlands. ${ }^{3}$ Utrecht University of Applied Sciences, Utrecht, The Netherlands.

\section{Received: 28 April 2020 Accepted: 3 November 2020} Published online: 01 December 2020

\section{References}

1. Fischer K, Ljung R. Primary prophylaxis in haemophilia care: guideline update 2016. Blood Cells, Mol Dis. 2017;67:81-5.

2. Nilsson IM, Berntorp E, Lofqvist T, Pettersson H. Twenty-five years' experience of prophylactic treatment in severe haemophilia A and B. J Intern Med. 1992 Jul;232(1):25-32.

3. Schrijvers $\mathrm{LH}$, Cnossen MH, Beijlevelt-van der Zande M,Peters $\mathrm{M}$, Schuurmans MJ, Fischer K. Defining adherence to prophylaxis in haemophilia. Haemophilia. 2016;22:e301-48.
4. Schrijvers LH, Beijlevelt-van der Zande M, Peters M, Lock J, Cnossen MH, Schuurmans MJ, et al. Adherence to prophylaxis and bleeding outcome in haemophilia: a multicentre study. Br J Haematol. 2016;174:454-460.

5. Geraghty S, Dunkley T, Harrington C, Lindvall K, Maahs J, Sek J. Practice patterns in haemophilia A therapy - global progress towards optimal care. Haemophilia. 2006;(12):75-81.

6. Lindvall K, Colstrup L, Wollter IM, Klemenz G, Loogna K, Grönhaug S, et al. Compliance with treatment and understanding of own disease in patients with severe and moderate haemophilia. Haemophilia. 2006;12:47-51.

7. Hacker MR, Geraghty S, Manco-Johnson M. Barriers to compliance with prophylaxis therapy in haemophilia. Haemophilia. 2001;7(4):392-6.

8. Fischer K, Van Der Bom JG, Molho P, Negrier C, Mauser-Bunscho-Ten EP, Roosendaal G, et al. Prophylactic versus on-demand treatment strategies for severe haemophilia: a comparison of costs and long-term outcome. Haemophilia. 2002;8:745-52.

9. Nijdam A, Foppen W, de Kleijn P, Mauser-Bunschoten EP, Roosendaal G, van Galen KPM, et al. Discontinuing early prophylaxis in severe haemophilia leads to deterioration of joint status despite low bleeding rates. Thromb Haemost. 2016;115:931-8.

10. Klamroth R, Pollmann H, Hermans C, Faradji A, Yarlas AS, Epstein JD, et al. The relative burden of haemophilia $A$ and the impact of target joint development on health-related quality of life: results from the ADVATE Post-Authorization Safety Surveillance (PASS) study. Haemophilia. 2011;17(3):412-21.

11. Jansen NWD, Roosendaal G, Bijlsma JWJ, Groot de J, Lafeber FPJG. Exposure of human cartilage tissue to low concentrations of blood for a short period of time leads to prolonged cartilage damage: an in vitro study. Arthritis Rheum. 2007:56(1):199-207.

12. Schrijvers LH, Kars MC, Beijlevelt-van der Zande M, Peters M, Schuurmans MJ, Fischer K. Unravelling adherence to prophylaxis in haemophilia: a patients' perspective. Haemophilia. 2015;21:612-21.

13. Bowen DJ, Kreuter M, Spring B, Linnan L, Weiner D, Bakken S, et al. How we design feasibility studies. Natl intitute Heal. 2009;36(5):452-7.

14. Eldridge SM, Chan CL, Campbell MJ, Bond CM, Hopewell S, Thabane L, et al. CONSORT 2010 statement: extension to randomised pilot and feasibility trials. Pilot Feasibility Stud. 2016;2(1):1-32.

15. Hayes SC, Pistorello J, Levin ME. Acceptance and commitment therapy as a unified model of behavior change. Couns Psychol. 2012;40(7):976-1002.

16. Hayes SC, Wilson KG. Acceptance and commitment therapy: altering the verbal support for experiential avoidance. Behav Anal. 1994;17(2):289-303.

17. Lindholm-Olinder A, Fischier J, Fries J, Alfonsson S, Elvingson V, Eriksson JW, et al. A randomised wait-list controlled clinical trial of the effects of acceptance and commitment therapy in patients with type 1 diabetes: a study protocol. BMC Nurs. 2015;14(1):61.

18. Moitra E, Herbert JD, Forman EM. Acceptance-based behavior therapy to promote HIV medication adherence. AIDS Care - Psychol Socio-Medical Asp AIDS/HIV. 2011;23(12):1660-7.

19. Pielech M, Vowles $K$, Wicksell R. Acceptance and commitment therapy for pediatric chronic pain: theory and application. Children. 2017;4:10.

20. Dalton JA, Coyne P. Cognitive-behavioral therapy: tailored to the individual. Nurs Clin North Am. 2003;38(3):465-76.

21. de Ridder D, Schreurs K. Developing interventions for chronically ill patients. Clin Psychol Rev. 2001;21(2):205-40.

22. Ammerlaan JW, Mulder OK, de Boer-Nijhof NC, Maat B, Kruize A, van Laar J, et al. Building a tailored, patient-guided, web-based self-management intervention 'ReumaUitgedaagd!' for adults with a rheumatic disease: results of a usability study and design for a randomized control trial. JMIR Res Protoc. 2016;5(2):e113.

23. Lorig KR, Sobel DS, Stewart AL, Brown BW, Bandura A, Ritter P, et al. Evidence suggesting that a chronic disease self-management program can improve health status while reducing hospitalization a randomized trial. Med Care. 1999;37(1):5-14.

24. Craig P, Dieppe P, Macintyre S, Michie S, Nazareth I, Petticrew M. Developing and evaluating complex interventions: the new Medical Research Council guidance. Bmj. 2008;1655(September):a1655.

25. Schrijvers LH, Uitslager N, Schuurmans MJ, Fischer K. Barriers and motivators of adherence to prophylactic treatment in haemophilia: a systematic review. Haemophilia. 2013;19:355-61.

26. Duncan NA, Kronenberger W, Roberson C, Shapiro A. VERITAS-Pro: a new measure of adherence to prophylactic regimens in haemophilia. Haemophilia. 2010;16(2):247-55. 
27. Brazier JE, Harper R, Jones NM, O'Cathain A, Thomas KJ, Usherwood T, et al. Validating the SF-36 health survey questionnaire: new outcome measure for primary care. BMJ. 1992;305(6846):160-4.

28. Broadbent E, Petrie KJ, Main J, Weinman J. The Brief Illness Perception Questionnaire. J Psychosom Res. 2006;60(6):631-7.

29. Osborne RH, Elsworth GR, Whitfield K. The Health Education Impact Questionnaire (heiQ): an outcomes and evaluation measure for patient education and self-management interventions for people with chronic conditions. Patient Educ Couns. 2007;66(2):192-201.

30. Hays RD, Morales LS. The RAND-36 measure of health-related quality of life. Ann Med. 2001;33(5):350-7.

31. Van Meijel B, Gamel C, Van Swieten-Duijfjes B, Grypdonck MHF. The development of evidence-based nursing interventions: methodological considerations. J Adv Nurs. 2004;48(1):84-92.

32. Ammerlaan J, van Os-Medendorp H, de Boer-Nijhof N, Scholtus L, Kruize AA, van Pelt $P$, et al. Short term effectiveness and experiences of a peer guided web-based self-management intervention for young adults with juvenile idiopathic arthritis. Pediatr Rheumatol. 2017;15(1):1-13.

33. Ruiz F. A review of acceptance and commitment therapy (ACT) empirical evidence: correlation, experimental, sychopathology, component and outcome studies. Int J Psychol Psychol Ther. 2010;10:125-62.

34. Graham CD, Gouick J, Krahé C, Gillanders D. A systematic review of the use of Acceptance and Commitment Therapy (ACT) in chronic disease and long-term conditions. Clin Psychol Rev. 2016;46:46-58.

35. Lam WY, Paula F. Medication Adherence Measures: An Overview. BioMed Res Int. 2015.

36. Plug I, Van Der Bom JG, Peters M, Mauser-Bunschoten EP, De Goede-Bolder $A$, Heijnen $L$, et al. Thirty years of hemophilia treatment in the Netherlands, 1972-2001. Blood. 2004;104(12):3494-500.

37. Cassis F, Emiliani F, Pasi J, Palareti L, lorio A. Psychological interventions for people with hemophilia. Cochrane Database Syst Rev. 2020;(3):1-61.

38. Ammerlaan JW, Scholtus LW, Drossaert CH, van Os-Medendorp H, Prakken B, Kruize AA, et al. Feasibility of a website and a hospital-based online portal for young adults with juvenile idiopathic arthritis: views and experiences of patients. JMIR Res Protoc. 2015:4(3):e102

39. Sloot R, Flinterman L, Heins M, Lafeber M, Boeije H, Poos M. Reumatische aandoeningen in Nederland: Ervaringen en kerngetallen. Nivel. 2016:3-133.

40. Marrie RA, Walker JR, Graff LA, Patten SB, Bolton JM, Marriott JJ, et al. Gender differences in information needs and preferences regarding depression among individuals with multiple sclerosis, inflammatory bowel disease and rheumatoid arthritis. Patient Educ Couns. 2019;102:1722-9.

41. Abbey SE, Shnek ZM, Irvine J, Grace SL. Gender differences in health information needs and decisional preferences in patients recovering from an acute ischemic coronary event. Psychosom Med. 2004;66(1):42-8.

42. Davey J, Holden CA, Smith BJ. The correlates of chronic disease-related health literacy and its components among men: a systematic review. BMC Public Health. 2015;15(1):1-25.

43. Deeks A, Lombard C, Michelmore J, Teede H. The effects of gender and age on health related behaviors. BMC Public Health. 2009;9:1-8.

44. Thoolen B, De Ridder D, Bensing J, Gorter K, Rutten G. Who participates in diabetes self-management interventions?: issues of recruitment and retainment. Diabetes Educ. 2007;33(3):465-74.

\section{Publisher's Note}

Springer Nature remains neutral with regard to jurisdictional claims in published maps and institutional affiliations.

Ready to submit your research? Choose BMC and benefit from:
- fast, convenient online submission
- thorough peer review by experienced researchers in your field
- rapid publication on acceptance
- support for research data, including large and complex data types
- gold Open Access which fosters wider collaboration and increased citations
- maximum visibility for your research: over 100M website views per year
At BMC, research is always in progress.
Learn more biomedcentral.com/submissions

